\title{
1. Introduction to learning and teaching health economics
}

\author{
Allen C. Goodman and Maia Platt
}

As a distinct and exciting field, health economics (HE) is still considered a relative newcomer in the world of economic sciences. In a discipline with a venerable history in international trade, public finance, and industrial organization, along with core fields such as microeconomics, macroeconomics, and econometrics, only within the last 30 years has HE been introduced into mainstream university economics offerings. Most academic programs leading to undergraduate or graduate level HE specializations are housed in economics departments, or within economics groups housed in health professions/services department settings.

HE courses, in contrast, often reside outside of economics departments, in schools of public health, health professions, health sciences, nursing, pharmacy, business, or public/health administration. Many students in the health professions, as well as other non-economics majors, have never taken an economics course before enrolling in health economics. In fact, HE courses are often taught by non-economists, particularly when housed in smaller and more remote settings.

Within this context, we present a volume of some of the best teaching practices that have evolved in the field over the past decade. We expect that the volume will serve HE instructors with or without professional training in HE, and that its practical applications will encompass HE courses taught in various economics and non-economics undergraduate, graduate, and professional programs. We have sought to expand applicability beyond North America and Western Europe, to address issues in both less developed health economies and more advanced ones.

As we prepare this volume in mid-2021, when the COVID-19 pandemic has drastically impacted the teaching of HE in so many ways, we feel it is important to bring the readers' attention to at least two pivotal points. First, the study of healthcare, health efficacy, health policy, and health research have been pushed to the front of the academic line. Questions relating to the allocation of healthcare resources, payment for health services, and research and development of vaccines have sprung forward, as well as more difficult questions such as the trade-off between public health interventions (closing down sectors of the economy to slow the spread of disease) and the accompanying economic dislocations.

Second, at least temporarily, within-classroom instruction has virtually disappeared in much of the world, and the need for innovative remote teaching methods has become critical. While the current crisis will pass, the movement toward more remote forms of instruction, already manifested in online and distance learning, was growing before the pandemic. Many universities will re-evaluate their mix of offerings, and many instructors may overcome their resistance and move to a fuller embrace of innovative remote methods.

We seek to make this opening chapter more than simply an ordered synopsis of the book's forthcoming chapters. Instead, we also wish to write briefly about the beginnings of HE and 
HE education, and to define four key organizing principles used in this volume, as we enter the third decade of the 2000s:

- Active learning assignments;

- Teaching tips and tools for the online environment;

- International and country-specific perspectives and applications; and

- Dissemination and societal impact of HE skills.

While none of these principles is unique to HE, the field is taught in a variety of settings and delivery modalities. This variety provides important challenges to those designing curricula, creating teaching materials, and using them in either in-person or virtual learning environments.

\section{THE BEGINNINGS OF HEALTH ECONOMICS}

Nobel laureates Milton Friedman and Simon Kuznets (Friedman and Kuznets, 1945) and Reuben Kessel (1958), among other prominent economists, wrote on HE topics in the first part of the twentieth century. Friedman and Kuznets looked at the differential earnings of physicians and dentists, while Kessel examined the ability of physicians to increase earnings by segmenting the consumer market.

Many date the definition of the health economics field to an article by Kenneth Arrow in 1963. In his seminal work 'Uncertainty and the Welfare Economics of Medical Care' (as part of a research agenda commissioned by the Ford Foundation), Arrow noted the difficulty in predicting health outcomes. These prediction problems make it complicated to develop markets for risk sharing, and properly functioning health insurance markets may fail to develop. To address these problems, Arrow argued that healthcare markets must rely on institutions such as licensure of physicians and institutional norms. Potential failures of private insurance markets may lead to large numbers of uninsured people and to the potential or necessity for governments to step in either to fix the existing markets, or to create new ones.

This insight was particularly important, because much of Arrow's earlier work (particularly with Gerard Debreu in 1954) on the economic theory of competitive markets had assumed the existence of complete markets to insure against all risks. His recognition of insurance-related problems implied that economists could provide thoughtful theoretical and empirical insights into a host of issues specific to the healthcare industry in particular. A short but very influential follow-up article by Mark Pauly (1968) that emphasized and clarified issues of insurance-related moral hazard, moved health economics toward 'field' status by the early 1970s.

Economists' early efforts ran into considerable opposition from many in the health and health services communities. Some healthcare providers and health policy-makers argued that because neither consumers nor providers paid attention to economic factors such as costs or prices when making decisions, that the costs or prices (often related to insurance) were meaningless. Others argued that health or healthcare is a right, and that we should not make decisions based on economic or market factors.

Still, as the health expenditure share of the Gross Domestic Product in the United States surpassed 10 percent in the 1980s and moved toward the current 18 percent, with similar (although smaller in magnitude) increasing trends across almost all other countries, it became 
clear that resources devoted to healthcare had become large, and that they came at the expense of other societal needs and expenditures. It also became clear that economic scarcity matters in the healthcare sector and beyond.

Health economics has gained a foothold both in economics departments, particularly at the undergraduate level, and in many other higher education programs (public health, nursing, medicine, pharmacy, business) that address the healthcare economy. Teaching in these diverse, specialized curricula requires a customized subset of methods and materials developed for both the instructors and the students.

\section{TEACHING MATERIALS}

For many decades, much of the traditional economics instruction followed the familiar 'chalk and talk' format wherein the instructor lectures within a physical classroom. Those choosing to teach HE usually came from specialties in applied microeconomics (often labor or industrial organization), and because most had not specialized in HE, the availability of good textbooks was particularly important. A number of excellent HE texts entered the market, starting with Feldstein (1979), followed by Phelps (1992), Folland et al. (1993), Santerre and Neun (1996), Getzen (1997), Henderson (1998), and numerous others more recently. These books have had multiple editions, and over time most have come to provide instructor's guides, small test banks (particularly with the advent of online courses), and limited presentation (e.g., PowerPoint) materials.

In the context of the publishing industry, the target audience for HE books is 'small' compared with large-volume Principles (micro/macro) texts that come with enormous varieties of (expensive) instructor features. 'Big' texts offer test banks with thousands of questions, dynamic presentation materials (which can read and/or translate the text for the student), web-based author presentations, and seamless 'synching' with instructional platforms such as Blackboard or Canvas. Publishers of 'small' texts (most middle-level economics field texts are 'small' texts) simply cannot afford such features, and they do not provide them. In fact, some 'big text' publishers divested themselves of most of their 'small' properties around 2015. Instructors in the smaller specialty fields are therefore left to develop materials either by themselves or in a community.

A number of prominent communities have developed to support the teaching of HE. Since 2011, the International Health Economics Association (iHEA) has taken a lead in promoting the teaching of health economics (THE) through a series of pre-congress workshops in Toronto (2011), Dublin (2014), Milan (2015), Boston (2017), and Basel (2019). An additional pre-conference workshop occurred at the American Society of Health Economists (ASHEcon) meetings in 2018. Teaching Health Economics Pre-Congress Session Recordings from the 2017 World Congress in Boston are available online (iHEA, 2017).

Separately, in 2013 a group of United Kingdom health economists developed the Health Economics education (HEe) website (Economics Network, 2013). This online educational resource sought to: (1) encourage the teaching and learning of HE; (2) support teaching and learning in HE; (3) create a community of HE teachers willing to share ideas, resources and expertise; and (4) promote HE to potential students (Frew et al., 2018). This website required considerable external funding and management, as well as a dedicated group of leaders including Emma Frew and Heather Brown. 
Subsequent to the 2017 Boston meetings, iHEA started a comprehensive online repository of HE teaching materials (iHEA, 2018), where content from the HEe website is now incorporated as well. This worthy effort seeks to support and enhance capacity for HE teaching by sharing resources. Frew and colleagues (2018) note that since HE is often taught outside of economics departments and sometimes by teachers with very little economics training, it is challenging and important to improve awareness of this resource and to boost engagement 'to foster a vibrant, active community of health economics teachers'.

This volume draws from contributors to the 2017 and 2019 iHEA meetings, the 2018 ASHEcon meetings, and a small number of additional authors. Our contributors come from five continents and multiple teaching settings. The works are original contributions that have not been published elsewhere. There was no explicit organizing principle at the outset; however, as noted above, four (non-exclusive) categories emerged: (1) Active Learning Assignments; (2) Teaching Tips and Tools for Online Environment; (3) International and Country-Specific Perspectives and Applications; and (4) Dissemination and Societal Impact of HE Skills. We discuss these in the following sections.

\section{Active Learning Assignments}

The classroom setting has traditionally defined the teaching enterprise. Since the 1970 s, classroom instructors have moved from the traditional blackboard (or whiteboard) to the use of transparencies with a projector, to the near-ubiquitous use of presentation software such as Microsoft PowerPoint. Even 'flipping the classroom', which inverts the conventional notion of classroom-based education (students acquire knowledge before the class and then use classroom time to practice and apply concepts and ideas through interaction with peers and teachers) still (most often) occurs within a conventional classroom setting.

Departing from the 'chalk and talk', our contributors describe novel applications that include an insurance game, a semester-long creation of a healthcare system for a new country, innovative lab exercises and computerized applications, the creation of research portfolios and use of competencies-based approach in teaching. School policies on in-person instruction due to COVID-19 may result in some permanent shifts away from in-person instruction. Yet one can use the insights and innovative approaches adopted through online and distance learning to consider how these applications may be adapted for different instructional modalities.

Jennifer Kohn's Health Insurance Game (HIG), discussed in Chapter 2, gives participants first-hand shared experience 'buying' and 'selling' health insurance under a variety of policy regimes. Within this classroom exercise, the HIG framework is flexible enough to accommodate not only different policies, but also different academic backgrounds, math abilities, class sizes, and time frames.

Within a classroom, participants buy and sell insurance under several different scenarios of information availability (perfect information, asymmetric uncertainty or symmetric uncertainty) and policy restrictions (from free market to universal healthcare and anything in between). Participants act either as consumers or insurers and can change roles through different rounds of the game to experience both sides of the transaction. Throughout the different rounds of the game, consumers choose whether to purchase insurance and insurers choose what to charge. The goal of the game for both consumers and insurers is to end the round (or several rounds) with the most money (of all the participants). 
While the HIG was originally designed for the US institutional setting, it has been adapted and played in several countries with different systems, including government single-payer. It provides key insights regarding adverse selection, moral hazard, and the unintended consequences of various policy constraints that apply across health systems and that simply do not emerge from more passive presentations.

In Chapter 3, Neha Batura and colleagues introduce readers to the portfolio method of assessment from an HE course taught at University College London. The student's portfolio is a collection of work that usually includes a written reflective summary, submitted as evidence that learning has taken place. The authors outline a material list and pre-work required by students for preparation before and after the teaching has been delivered. They also provide teaching tips to aid implementation of the portfolio, along with key takeaway messages for implementers.

Portfolios can enable assessment of varied tasks and of progression over time and thus provide the course instructors with an accurate picture of the students' ability to:

- grasp theoretical concepts and apply them to tasks;

- incorporate formative feedback from diverse sources such as peer/tutor feedback, as well as independent reading, and incorporate those into the reflection;

- develop arguments and critically engage with current debates or hot topics.

While the grading load is less than that of exam- or essay-based assessments, grading portfolios can nevertheless be challenging. The authors develop clear grading criteria and recommend setting up an initial markers' meeting to help graders and students.

In Chapter 4, Carolyn Dewa and Jeffrey Hoch discuss the use of laboratory exercises (in economics!) that have been refined over 20 years of use in the classroom to teach HE principles to students in health professions. They describe the context for which these labs were created, including the educational program, course learning objectives, course material, and time plan. The first lab covers core concepts underlying health insurance. The second reviews economic evaluation methods and the concept of opportunity cost.

Their course material is calibrated for graduate students in an Executive Master of Health Administration program housed at the University of California - Davis. Typically, the mid-career learners are seeking to develop or improve management and administrative skills in a structured formal educational setting, and they represent a diverse set of disciplines such as medicine, nursing, physical therapy, clinical trials research, diagnostic/laboratory, and administration.

The authors foster a basic understanding of how to apply economics principles to healthcare management, but their applications are suitable for students in other health professions as well. Eschewing detailed discussion of the importance of the concepts, they direct the labs at students who have had experience purchasing health services and making insurance coverage decisions. The course focuses on health economic and microeconomic concepts underlying the structure of the existing healthcare delivery systems. The authors emphasize that the course goal is not to create health economists. Rather, it seeks to provide learners with opportunities to develop an understanding of, and the skills to use, economic concepts and analyses for decision-making in healthcare environments.

The next two offerings in this section are a bit more complex. Michal Horný provides a challenging, yet rewarding, treatment of Monte Carlo simulations in Chapter 5. Horný notes that applied HE builds upon advanced probabilistic and statistical foundations, and that complex 
stochastic methods such as the Monte Carlo simulation are now commonly used in HE evaluations. Learning such abstract concepts may prove challenging for students without strong backgrounds in quantitative and statistical methods.

The chapter describes an in-class exercise to demonstrate actively (by moving around a room) the conceptual differences between deterministic and stochastic modeling, as well as between first-order (also known as micro-simulation or random walk) and second-order (also known as probabilistic sensitivity analysis) Monte Carlo simulation techniques. The primary objective of this active learning exercise is to improve students' comprehension and long-term retention of these abstract concepts.

One of Horný's key takeaways (and a theme echoed by other contributors) is that course instructors can save time by using decision problems and underlying model structures that the students have already encountered. For example, instructors may use decision problems ultimately intended for this learning activity in early homework assignments. By doing so, students become familiar with the decision problem, its background story, the underlying model structure, as well as the meaning of all model parameters before the activity. This underlying familiarity makes the introductions of the models themselves almost effortless for the Monte Carlo simulation exercise.

In the following chapter (Chapter 6), Jeffrey Hoch and Carolyn Dewa apply regression models to some familiar methods of economic evaluation. Cost-effectiveness analysis (CEA) estimates the extra cost $(\Delta \mathrm{C})$ and the extra effect $(\Delta \mathrm{E})$ of a new treatment or intervention compared with usual care. The main statistics in CEA involve means and differences in means. Students are generally comfortable calculating arithmetic means using the standard formula, but they may need a reminder that regression can estimate both means and differences in means. This insight is very helpful in the analysis of a cost-effectiveness dataset.

This chapter's exercise gives students an opportunity to 'do a CEA'. The authors show how a cost-effectiveness dataset includes three types of information: cost, outcome (or 'effect') and treatment data. Students calculate two different cost-effectiveness statistics, the Incremental Cost-Effectiveness Ratio (ICER), and the Incremental Net Benefit (INB). In addition to producing estimates, students learn how to characterize statistical uncertainty. This is facilitated through learning about the INB both as a difference in means as well as a net benefit regression estimate.

Florian Buchner's Noricum experiment (Chapter 7) emerges from a consulting project for the World Health Organization (WHO) that originated in Kosovo, shortly after the end of the Kosovo war in 2000. The author's task was to develop a new insurance copayment system. By the end of the project, he reports, all the recommendations were put into law, but he also makes an important conclusion that in reaching this goal 'there were some dead ends. Unfortunately, ... dead ends are often part of the story'. The Kosovo task was not unique. Buchner notes several periods of reconstruction with their implications for healthcare systems, such as at the beginning of the Weimar Republic after World War I, or the development and implementation of the 'social market economy' in the Federal Republic of Germany after World War II.

Noricum lays bare the continuous conflicts of interests among healthcare system stakeholders. Using a sophisticated role-playing format, healthcare management students reorganize a healthcare system for a fictitious country. The students organize themselves into subgroups, take the roles of central stakeholders, prepare their political strategies, and negotiate contracts and legislation to (re)structure Noricum's healthcare system. Students and instructors 
reconsider the resulting healthcare system and the process of its development in a feedback workshop, and the students reflect individually about the results of the whole process.

The core teaching concept rests on a considerable amount of freedom for students which they often find quite challenging. The groups' actions are followed by comprehensive feedback. More than ten cohorts of students have generated numerous Noricum plans over the years, and Buchner discusses the concept in detail, in the context of making the learning visible to the students.

Elizabeth Seidler (Chapter 8) concentrates on teaching HE competencies. Traditional economics curricula do not think in terms of competencies, but a variety of programs in the health professions do. Seidler notes that the demographics and modality of graduate programs in Health Administration, Healthcare Management and other graduate programs that require or offer a course in HE have changed in recent years, but the need for modified HE instruction in these programs and the difficulties that students encounter while learning health economics continues as an instructional challenge. Students enrolled in these programs typically do not have previous (or recent) instruction or experience in microeconomic principles or theory. Students without backgrounds in economics are concerned about their ability to navigate and complete the HE requirement successfully. In short, some students in these programs are afraid of economics.

For readers interested in teaching methods and teacher certification, Seidler also refers to pedagogical improvements such as elements of the Effective Teaching Practices (ETP) certificate offered by the Association of College and University Educators (ACUE). She also cites the Universal Design for Learning (UDL) whose guidelines refer to providing multiple options for: (1) perception; (2) language, mathematical expressions and symbols; and (3) comprehension.

\section{Teaching Tips and Tools for the Online Environment}

Distance learning is hardly new. Kassis (2012) observes that correspondence courses have been available for over 200 years, since the development of a reliable postal service. Radio and television courses became available with their respective media. Early specialized users of distance education, such as the US Armed Forces, needed to teach the same materials to personnel separated by distance and time zones. However, the explosion of Internet resources has fueled and supported a corresponding explosion of distance education, with issues of content and quality becoming paramount.

The sudden push to distance education in March 2020 generated a substantive set of questions including:

- Are the necessary hardware and bandwidth infrastructures to do this available either in the short term or the long-term? Using Skype or Zoom for regularly scheduled meetings is very different from using them for occasional meetings. Most instructors do not have production studios in their homes. Many students have either slow or no internet connections.

- Are appropriate materials available to provide high-quality online courses? While many instructors do not seek professional production quality, an unfocused webcam along with a droning voice, and inadequate video, will simply not substitute for a vibrant in-person lecture. 
- How much of a tuition differential would students be willing to pay for online education at an Ivy League school compared with a nationally unranked online university or even online (local) community college?

These questions merit much more scholarly attention. Our contributors to online learning address some of the key issues of online education. One cannot successfully put a course online simply by sitting in front of a laptop webcam and reading a lecture. In Chapter 9, Neil Meredith provides an outstanding 'how-to' manual that should comprise the first reading for anyone who wants to start teaching online. This chapter draws on Meredith's experience and research to develop recommended best practices for choosing a textbook, producing course videos, role-playing discussion forums, and creating random block examinations when teaching HE online asynchronously.

Meredith starts by presenting the notion of an 'ideal textbook'; one that comes with pre-built slides, fits the student audience, provides some practice exercises, and has a relatively long shelf life - a textbook that unfortunately does not exist in the HE field. His chapter continues with a collection of detailed tips and tools for how to teach one's very best HE course online in the absence of such a textbook. One of his recommendations is to produce (and he explains how) both high-quality, short, introduction videos and as many minimally edited videos as possible.

To improve learning and engagement in discussion forums, Meredith suggests a role-playing discussion forum. He also advocates random block examinations with time and visibility constraints to deter academic dishonesty. The chapter concludes with a final recommendation for other helpful resources such as the Teaching Health Economics Special Interest Group within the iHEA.

Femi Ayadi observes in Chapter 10 that online education is the 'new normal'. This has occurred through the significant improvements in online teaching technology over the years, and in light of the recent global COVID-19 pandemic and the subsequent stay-at-home requirements all over the world. Echoing Meredith's chapter, she notes that while electronic textbooks and interactive homework platforms are available in virtually every subject, the market for HE textbooks has traditionally not been large enough to provide a variety of interactive electronic HE texts and materials. Ayadi's teaching approach is to combine one interactive electronic text (even though it may not be specific to HE) with a 'non-interactive' HE text, to get the best of both worlds.

Providing quality content, however, says Ayadi, is difficult, particularly when the content is located on differing learning platforms. She seeks to eliminate the students' need to log on and engage with two different platforms each week. Using a Principles text (with health examples) with a good interactive platform is a start, but she notes resistance among students who resent paying for a text from which they use only a few chapters. She cites a 'serious and immediate need' for a high-quality interactive HE textbook and urges authors to work with publishers to create interactive e-textbook versions of their textbooks. It would be ideal to supplement these new texts with adaptive online homework platforms to provide choices in the HE textbook market, as well as to have such options open to all levels of HE students.

Ayadi also recommends cell phone apps to help engage students. Although many such apps are available around the world, Remind.com provides a modern way to stay engaged with students by text messages without having to exchange phone numbers. Socrative.com helps 
instructors to conduct short assessment quizzes. Students can download Socrative.com onto their phones to take the assessment, or they can log on via a website provided.

In Chapter 11, Heather Brown considers the use of case studies to outline potential mechanisms for engaging distance learners with no economic background. With the recognition of the importance of HE for healthcare decision making, increased numbers of healthcare professionals are deciding to undertake HE modules as part of their continuing professional development programs. Brown outlines some of the challenges of teaching for this group. She then discusses some of the pedagogical theory which informs the development of a range of activities to foster engagement.

Brown describes the online module for students in a Master of Science in Oncology and Palliative Care program and provides examples of activities, including a Market Failure Exercise. She views the development of course activities as an ongoing process, by showing how these activities were revised after reflecting on their design for fostering engagement and learning. She concludes with ideas about how these exercises can be used in practice and some areas that should be considered by teachers wishing to implement these exercises.

Perhaps the most important issue facing online educators is 'equivalence' to other (generally more traditional) forms of instruction (Gold and Watts, Chapter 12 in this volume). If there is a 'best' way to teach a course (in terms of educational outcomes), how close does distance learning come to that, and how do we know? The sudden transformation in 2020 of in-class instruction into distance learning modes, with unknown duration, has afforded new urgency to these questions.

The second important organizational aspect addresses teaching 'where you are' and 'when you are'. Many students take online courses precisely because they cannot get to the teaching location, or they cannot take a course at the time that it is offered. Addressing the 'where and when' problem often requires the use of asynchronous teaching methods, and our contributors address these methods in a variety of ways.

A third issue, implicit to all of these online discussions, is that one cannot provide high quality online instruction 'on the cheap'. Producing good videos requires professional direction and equipment. Setting up asynchronous instruction and exam sites is complicated and expensive. Although tempting to budget-conscious university administrators, scaling up small online courses by factors of two, five, or ten, requires careful attention and quality control.

Lisa Gold and Jenny Watts (Chapter 12) explore the opportunities and challenges in delivering formal education programs online in postgraduate HE through a case study of a postgraduate program delivered by their home institution, Deakin University, in Australia. A suite of postgraduate programs (including a Master of Health Economics) at Deakin is delivered either fully online, fully on-campus or partially online and partially on-campus, where each student can complete their program by choosing any of the three methods of delivery. Off-campus can include all of Australia, New Zealand, and indeed around the world.

All subjects or units have dual enrolment modes and are taught to all students simultaneously. Gold and Watts document the quest for equivalency in such a curriculum and discuss the challenges and successes of this approach. This quest is ongoing and merits much more discussion and pedagogical advance.

Diane M. Dewar (Chapter 13) focuses on four distance educational modalities: asynchronous platforms, teleconferencing, Skype sessions and email correspondence, for courses that are set up at different locations, both within the United States and around the world. With many years of expertise, Dewar uses a case study approach to highlight the alternatives in 
distance education that lend themselves well to teaching economics to college students. Her case studies include:

1. A joint HE course by two local colleges in upstate New York,

2. Short courses offered via teleconferencing nationwide for a certificate program,

3. Lectures via teleconference delivered to a Latin American university, and

4. Semester-long courses delivered to a medical school in Vietnam via a combination of face-to-face learning and teleconferencing.

Dewar's case studies touch upon the logistic, cultural, and evaluative issues observed in the distance education experience in all four cases. They also examine issues both unique to each modality as well as issues common to all modalities used. Dewar carefully presents her cases in order of increased complexity and summarizes some of the key factors that lead to enhanced learning experiences.

At the time of writing, universities around the world face the probability of an online teaching presence that was unfathomable before. In mid-May 2020, the California State University system (with over 500000 students) announced that with the possible exception of some laboratory and nursing classes, its entire Fall 2020 curriculum would be online (Chang and Pao, 2020). Others followed. In Chapter 14, Jill Herndon synthesizes many of the experiences of our contributors who had to make these rapid changes in the HE courses they were teaching at the time, describes strategies for adapting to the unexpected, and notes important considerations when implementing fundamental changes.

Herndon discusses the distinctions between synchronous and asynchronous learning. Synchronous learning does not require that all activities be synchronous, but instructors should identify opportunities to allow for real-time faculty-student interaction. It may be that a blend of synchronous and asynchronous activities is optimal for many HE teaching activities.

There is also growing recognition that the 'stopgap' solutions that worked for the last part of the 2019-2020 academic year do not 'have legs' for the long term. University professors who put PPT presentations online for the last few weeks of the Winter 2020 term recognized that they must do more in the longer term. This will require considerable new preparation for an unspecified length of time. As noted above, reading lectures into a webcam will not suffice.

There is also uncertainty on the 'buyer' end. Many university students have experienced difficulties (including inadequate computer or connectivity resources, lack of access to instructors, and lack of study space at home) in adjusting to a largely online teaching approach. As was noted earlier, some students have also balked at paying 'full tuition' for what they consider less than 'full education'.

\section{International and Country-Specific Perspectives and Applications}

In teaching other fields of economics, international perspectives are convenient, but often not essential. One can teach US students about monopoly, or housing markets, or public finance, largely using US examples. Convenient Internet resources, as well as databases from US agencies can support this inquiry easily.

Health economics instructors must look at international resources for several reasons. First, the healthcare system in the United States spends over 18 percent of the US Gross Domestic Product. No other country comes within five percentage points of that, and it is important to discuss why. Second, the United States, even under the Affordable Care Act, has tens of mil- 
lions of uninsured residents. No other advanced country faces this issue. Third, administrative costs and regulations provide major obstacles to good treatment in the United States.

Thus, meaningful international comparisons of health economies are essential, and examination of the healthcare systems around the world provides important resources for teaching and learning health economics. The four offerings in this section show how scholars on three continents use international resources in their HE courses.

In Chapter 15, Ashley Hodgson describes two uncommon out-of-class video-conferencing assignments that give students authentic interactions with people who may view healthcare systems from different perspectives. These assignments begin halfway through a HE course, after students have become familiar with key concepts and institutions in healthcare. In the first variation, students reach out to alumni from the college who work in the healthcare sector. The alumni contacts can range from nurses to health policy and pharmaceutical industry researchers. Students identify appropriate contacts through either a list maintained by the instructor or using the university's alumni directory. Students must then arrange a 30-60-minute videoconferencing call to discuss concepts related to healthcare economics and health systems. The instructor can provide a set of discussion questions to guide the conversation, but Hodgson encourages the students to follow the conversation 'where it goes'. After the video calls, students discuss in class the additional insights and anecdotes they learnt from their counterparts about the healthcare system, and the ways that this information illustrates HE concepts.

In the second variation of the assignment, the instructor collaborates with a colleague teaching in a different country. The two partners match their students in small groups for videoconferencing across classes. The 'home' class researches the other country's healthcare system before the videoconferencing, and their conversations are guided by discussion questions prepared mutually between the partners based on concepts that both classes have studied. As with the alumni version of the assignment, an in-class discussion allows students to share insights and anecdotes that they learned in their video calls and discuss how the calls impacted their understanding of healthcare economics. First presented to the HE teaching community at the 2017 iHEA meetings, this format has already proven to be remarkably successful to its numerous adopters across the world.

Simon Condliffe (Chapter 16) presents a series of four experiential learning exercises in which students seek to develop a variety of skills and knowledge related to international HE. The first exercise exposes HE students to international healthcare data that they use to produce a visualization. The second exercise asks students to apply econometric techniques to international health data and to think critically about relationships between life expectancy, GDP per capita and health expenditures per capita. The third exercise delves more deeply into the health systems of various countries. Students develop knowledge of and think critically about cross-country differences that underlie the data. In the fourth and final exercise, students meet with on-campus international students to discuss their respective healthcare systems. As Condliffe reports, for HE students in the United States, hearing first-hand testimonies about international healthcare systems has proven to be an invaluable learning experience. The first three exercises provide a springboard for HE students to have a rich discussion with their international peers.

Condliffe observes that putting a name (and a face) to stories of international healthcare systems underscores the differences in how this critical industry is organized elsewhere. These exercises not only offer students windows into international healthcare systems but also provide them with an alternative perspective to their own. Students are better prepared to 
discern what they like and dislike about certain healthcare systems, while acknowledging that each system has its own unique pros and cons.

Tommy Wilkinson and colleagues (Chapter 17) provide a general overview of the state of teaching health economics (THE) in sub-Saharan Africa, a region of 46 countries with 1.1 billion people which is observing a rapid expansion in health economics teaching. This is a region where the resources available to allocate 'are few and the constraints are heavy'.

Sub-Saharan Africa suffers from the lowest health outcomes, per-capita income and inequality of any region in the world. The authors identify key issues that impact teaching and teaching outcomes, and they provide case studies of institutions and major initiatives. They also identify the opportunities available to expand on recent gains in THE, harnessing the innovation and drive of people and institutions on the continent. Although the needs are stark, they expect that more and better HE teaching in the region will have a direct and substantive impact on decision-making, regulation, and policy, ultimately improving health equity and health outcomes from available resources - the goal of health economists everywhere.

A decade ago, writes Wilkinson, only a handful of institutions in sub-Saharan Africa taught any form of HE, with just two institutions offering formal degrees. The situation has improved, with new courses and degrees emerging in multiple countries across the continent. The authors conclude that THE in Africa has not yet achieved the critical mass of teaching institutions or student output to either address Africa's health policy challenges or come close to meeting demand for courses and instructors. They speak to the need for improved collaboration among various sub-Saharan institutions for course development, quality improvement, and supervision.

This section concludes with a contribution from Arturo Schweiger and colleagues (Chapter 18) who introduce readers to 'Study Abroad' programs. This chapter describes the experience of the 'International Module of Universidad Isalud' (IMUI) at Buenos Aires, Argentina. This one-week academic visit abroad of a group of Master's degree students in Health Economics and in Health Systems has been running since 1997. The chapter describes the preparation and development of academic activities.

As many who have participated in 'study abroad' activities already know, organization and planning are complicated. In selecting the location, organizers must consider Health Economics and Health Systems topics as well as the institutional agreements developed by the university in the area. The coordinating professor develops the schedule of the academic and social activities to cover. Only then can they open up the module to Master's students.

Schweiger and colleagues also provide a detailed set of evaluation components that could be tailored by users to their own programs. These include questionnaires directed toward the general course, the presentations, and the instructors. These materials provide an invaluable starting point for careful planning both of the trips, and the follow-up activities.

\section{Dissemination and Societal Impact of Health Economics Skills}

This section presents HE curriculum construction from the international perspectives of French Canada and Brazil. While economics instructors in these countries have English language texts or translations, those teaching HE often have more limited materials. They often teach non-economists, and they very often must work with the stakeholders who sponsor the course to determine the content and the approach. 
In Chapter 19, Maude Laberge and colleagues examine the creation of curricula and instructional materials to support patient-related capacity building and knowledge transfer in $\mathrm{HE}$ in Quebec, Canada. This extraordinary project describes collaboration between researchers and patients across the province with a particular concern for integrating patients into healthcare decision-making, teaching and research.

This case study presents an approach used to develop the services and training tools: tutorials, a protocol review service, a mapping of resources, in-person workshops and development of tools that could support integration of the patient perspective. It comprises a veritable handbook of best practices for conducting this kind of project.

The researchers argue that involving patients at various stages of teaching and research projects can contribute to identifying relevant outcomes and interpreting study results. The authors raise many questions and challenges in the process. These include determining the roles that patients can play, the methods to recruit the appropriate patients, and defining relevant patient engagement outcomes. Who would be better, they ask, than patients to understand and explain heterogeneity in results, irrespective of whether they are subjective preferences or objective health outcomes?

Tânia Maria Costa da Silva Beume investigates the teaching of HE to healthcare professionals in Brazil. Beume notes that Brazil is one of the few middle-income countries outside the Organisation for Economic Cooperation and Development (OECD) with a universal health system ensuring access to tax-financed primary and tertiary care. She catalogs the significant interest in HE by healthcare professionals but argues that it has been challenging to train healthcare professionals in HE.

The role of health economists highlights the importance of the partnerships between healthcare institutions and economics faculties to create a curriculum that combines healthcare-related disciplines, experience in the healthcare setting, and an adequate didactic background. Health economists teaching $\mathrm{HE}$ to healthcare professionals afford a broader perspective from the field of economics with positive consequences in health systems. Further, experience in healthcare settings gives economists the possibility of using active learning strategies based on real problems to enrich the transmission of knowledge of HE to healthcare professionals.

What about the future? Beume notes that many HE postgraduate courses offered as specializations or in masters or doctorate programs target healthcare professionals and non-economists, although economists are required to train healthcare professionals in HE. She thus proposes an option to expand the range of postgraduate courses offered for health economists, to provide more advanced understanding of healthcare industry economics, such as public health management, introduction to medical disciplines, and more.

\section{RESOURCES FOR TEACHING HEALTH ECONOMICS}

Outside of Neil Meredith's 'ideal textbook', with its ideal ancillary resources, it is important to map out some resources to help instructors excel in their teaching. The brief discussion here will necessarily relate to English-language resources, although comparable resources are available in other languages as well.

While the professional economics journals will often be difficult to read for beginning or even more advanced undergraduate students, journals such as Health Affairs seek to address health policy issues at an advanced layperson's comprehension. In the United States, the New 
York Times, the Wall Street Journal, and many large city newspapers have health sections with accessible stories and analyses. The Internet has brought international news sources into the classroom. Students enjoy looking at items both from home and abroad.

Websites such as the Commonwealth Fund (2020) or the Kaiser Family Foundation (2020) have a wealth of accessible analyses, that are also often available in PowerPoint or PDF format for insertion into lecture materials. OECD (2020) maintains an excellent website for health-related data from economically developed countries. English language readers can access websites of the National Institutes of Health (NIH, 2020), Centers for Disease Control and Prevention (CDC, 2020), Center for Medicare and Medicaid Services (CMS, 2020), as well as the Health Canada (2020), in both English and French, and the United Kingdom's National Health Service (NHS, 2020). Databases as well as explanatory analyses are available at these locations, and advanced students will cherish the opportunity to work on 'real data.'

Teaching resources have often been dispersed in many locations, but iHEA has been sponsoring dedicated sessions on Teaching Health Economics prior to each of its biannual World Congresses since 2011, and the iHEA online repository of HE teaching materials (iHEA, 2018 ) is a valuable resource for those who wish to start, and to improve their teaching. In the United States, the Journal of Economic Education (Taylor \& Francis Online, 2020) has long been a source of valuable teaching resources and ideas. In addition to dedicated sessions at the national meetings, and a standing committee on economic education, the American Economic Association (AEA) sponsors the annual Conference on Teaching and Research in Economic Education (CTREE) each May (AEA, 2020). This conference, which is dedicated to the teaching of economics, provides important opportunities for instructors to learn, present, and evaluate novel methods of teaching economics.

\section{READING THE BOOK}

In 2011, one of this volume's co-editors (Dr. Goodman) received a copy from our publisher, Edward Elgar Publishing, of the International Handbook of Teaching and Learning Economics, to which he had contributed a chapter on teaching health economics. When the (very large) volume arrived, he, of course, read his article, but then he started thumbing through other articles about teaching fields either unrelated, or only tangentially related to health economics. There was a lot to learn.

Through the ensuing decade, he also looked at chapters on distance education, assessment of learning, what economists think students should learn, and the creation of capstone courses. While the Internet has made searching much easier over the past three decades, and especially over the last ten years, it is convenient to have a set of innovative teaching materials all in one place.

With that in mind, we invite readers to sample the chapters. In 2021, distance learning has become very important, and this volume provides some important insights and practices. Some readers may seek new classroom exercises and methods. Many instructors work with web-based materials, some more comfortably than others. We try to provide guidance. We hope that this text provides important material not only to help instructors immediately in enriching their current course offerings and developing new ones, but also to help them grow as professional pedagogues and scholars. 


\section{REFERENCES}

AEA (2020), Past CTREE Annual Conferences, accessed 11 August 2020 at https://www.aeaweb.org/ about-aea/committees/economic-education/ctree-past

Arrow, K. J. (1963), 'Uncertainty and the welfare economics of medical care', American Economic Review, 53, 941-73.

Arrow, K. J. and G. Debreu (1954), 'Existence of an equilibrium for a competitive economy', Econometrica, 22 (3), 265-90.

CDC (2020), website, accessed 11 August 2020 at https://www.cdc.gov/

Chang, A. and M. Pao (2020), 'Cal State Chancellor says virtual classes can still lead to "lifetime of opportunity"', 14 May, accessed 9 July 2020 at https:/www.npr.org/sections/coronavirus-live -updates/2020/05/14/856243652/california-state-university-system-announces-plan-to-move-fall -semester-online

CMS (2020), website, accessed 11 August 2020 at https://www.cms.gov/

Commonwealth Fund (2020), website, accessed 11 August 2020 at https://www.commonwealthfund .org/

Economics Network (2013), Health Economics education (HEe) website, accessed 22 July 2020 at https://www.economicsnetwork.ac.uk/health

Feldstein, P. (1979), Health Care Economics, New York, NY, USA: Wiley.

Folland, S., A. C. Goodman and M. Stano (1993), The Economics of Health and Health Care, New York, NY, USA: Macmillan Publishing.

Frew, E., M. Platt, H. Brown, A. Goodman, E. Seidler, J. Spetz and D. McIntyre (2018), 'Building an international health economics teaching network', Health Economics, 27, 919-22.

Friedman, M. and S. Kuznets (1945), Income from Independent Professional Practice, New York, NY, USA: National Bureau of Economic Research.

Getzen, T. (1997), Health Economics: Fundamentals and Flow of Funds, New York, NY, USA: Wiley.

Health Canada (2020), website, accessed 11 August 2020 at https://www.canada.ca/en/health-canada .html

Henderson, J. (1998), Health Economics and Policy, Cincinnati, OH, USA: South-Western College Publishing.

iHEA (2017), Teaching Health Economics Pre-Congress Session Recordings, 8 July, accessed 22 July 2020 at https://www.healtheconomics.org/page/CongressRecordings

iHEA (2018), Health Economics Teaching Repository, accessed 22 July 2020 at https://www .healtheconomics.org/page/RepLP

Kaiser Family Foundation (2020), website, accessed 11 August 2020 at https://www.kff.org/

Kassis, M. M. (2012), 'Distance education: Course development and strategies for success', in G. M. Hoyt and K. McGoldrick (eds), International Handbook of Teaching and Learning Economics, Cheltenham, UK and Northampton, MA, USA: Edward Elgar Publishing, pp.160-166.

Kessel, R. (1958), 'Price discrimination in medicine', Journal of Law and Economics, 1, 20-53.

NHS (2020), website, accessed 11 August 2020 at https://www.nhs.uk/

NIH (2020), website, accessed 11 August 2020 at https://www.nih.gov/

OECD (2020), OECD Health Statistics, accessed 11 August 2020 at http://www.oecd.org/els/health -systems/health-data.htm

Pauly, M. V. (1968), 'The economics of moral hazard: Comment', American Economic Review, 58, 531-7.

Phelps, C. (1992), Health Economics, New York, NY, USA: HarperCollins Publishers.

Santerre R. and S. Neun (1996), Health Economics: Theories, Insights, and Industry Studies, Chicago, IL, USA: Irwin Publishing.

Taylor \& Francis Online (2020), The Journal of Economic Education website, accessed 11 August 2020 at https://www.tandfonline.com/loi/vece20 